\title{
Weakness of the Intracontinental Strike-Slip Kunlun Fault and Implications for Tibetan Tectonics
}

\author{
Weipeng Huang and Aiming Lin* \\ Graduate School of Science and Technology. Shizuoka University, Suruga-ku, Ohya 836, Shizuoka 422-8529, Japan
}

\begin{abstract}
An analysis of fault-related fold structures and the focal mechanisms of large earthquakes reveals that the maximum horizontal stress is oriented sub-perpendicular to the intracontinental strike-slip Kunlun Fault, which triggered the $1997 \mathrm{M}_{\mathrm{w}}$ 7.6 Manyi and $2001 \mathrm{M}_{\mathrm{w}} 7.8$ Kunlun earthquakes upon the northern Tibetan Plateau. Based on seismic inversion results and in situ measurements of stress performed immediately before and after the $2001 \mathrm{M}_{\mathrm{w}} 7.8 \mathrm{Kunlun}$ earthquake, a low shear stress of $<1 \mathrm{MPa}$ is estimated for the Kunlun Fault, which is an order of magnitude less than the shear strength obtained from laboratory measurements but compatible with that measured along the San Andreas Fault. Geological and geophysical evidence confirms that the Kunlun Fault is rheologically weak and that it plays an important role in accommodating eastward extrusion of the Tibetan Plateau in response to ongoing continental collision between the Indian and Eurasian plates.
\end{abstract}

Keywords: Fault strength, weakness, strike-slip, Kunlun Fault, Tibetan Plateau.

\section{INTRODUCTION}

Fault strength is an important factor in understanding the rupture mechanisms of large earthquakes and the rheological properties of seismogenic faults. Geological and geophysical evidence suggests that some crustal faults are weak compared with laboratory measurements of frictional strength [1-3]. In particular, the strength of the San Andreas Fault (SAF) has been the subject of debate for decades, with many studies concluding that the SAF is weak [2-5], although others argue otherwise [6,7]. Studies on fault strength are largely limited to the SAF, and a lack of geological and geophysical data for intracontinental active faults upon which large earthquakes repeatedly occur means that the topic of fault strength remains an area of contention. Accordingly, additional case studies and data on faults other than the SAF are needed to deepen our understanding of this fundamental but controversial problem.

In the present study, we focus on the strike-slip Kunlun Fault, one of the major intracontinental active faults in the Tibetan Plateau. We examine the strength of the Kunlun Fault based on analyses of fault-related fold structures developed upon late Pleistocene-Holocene alluvial fans around the fault, in situ measurements of stress obtained immediately before and after the $2001 \mathrm{M}_{\mathrm{w}} 7.8$ Kunlun earthquake, and the focal mechanisms of large earthquakes. We then discuss the implications of these findings for the collisional tectonics of the Tibetan Plateau.

\section{TECTONIC OUTLINE}

The Kunlun Fault is located within the Kunlun mountains of northern Tibet, at an average elevation of $>4500 \mathrm{~m}$. The fault strikes E-W to WNW-ESE and extends for $>1200 \mathrm{~km}$

*Address correspondence to this author at the Institute of Geosciences, Faculty of Science, Shizuoka University, Suruga-ku, Ohya 836, Shizuoka 422-8529, Japan; Tel/Fax: 81-54-238-4792; E-mail: slin@ipc.shizuoka.ac.jp
(Fig. 1). Geological and seismic data reveal that the fault is an active strike-slip fault, one of major active faults in the Tibetan Plateau. More than 10 moderate to large $(\mathrm{M}>6.0)$ earthquakes occurred on the Kunlun Fault over the past century, with four $\mathrm{M} \geq 7.0$ events having produced distinct surface rupture structures (Fig. 1), indicating that the fault is currently active [8-10]. Recent studies show that the rate of left-lateral displacement along the fault diminishes from 10$20 \mathrm{~mm} / \mathrm{yr}$ in the west to $2-3 \mathrm{~mm} / \mathrm{yr}$ in the east, at an average gradient of $1 \mathrm{~mm} / 100 \mathrm{~km} \mathrm{[10];} \mathrm{these} \mathrm{findings} \mathrm{are} \mathrm{consistent}$ with GPS observations [11]. The enormous length of the fault and high rate of displacement play an important role in the eastward extrusion of the Tibetan Plateau, accommodating the ongoing northward penetration of the Indian Plate into the Eurasian Plate [10-12].

\section{STATE OF STRESS NEAR THE KUNLUN FAULT}

Several instrumentally recorded large earthquakes have occurred upon the Kunlun Fault in recent decades, including the $1997 \mathrm{M}_{\mathrm{w}}$ 7.6 Manyi earthquake at the western extremity of the fault [13] and the $2001 \mathrm{M}_{\mathrm{w}} 7.8$ Kunlun earthquake in the central segment of the fault [9]. The focal mechanisms derived from these earthquakes indicate nearly pure strikeslip displacement and NNE-SSW compression along the entire fault (Fig. 1). This finding indicates that the maximum horizontal stress is oriented orthogonal to the Kunlun Fault, as with the SAF $[2,4]$.

Co-seismic surface deformation structures related to the Manyi and Kunlun earthquakes indicate strike-slip displacement and NNE-SSW compression, reflecting the orientation of the principal stress along the fault. The Kunlun earthquake produced a 400-450 km long co-seismic surface rupture zone along the pre-existing Kunlun Fault with an average strike-slip displacement of 3-7 $\mathrm{m}$ and the development of co-seismic mole track structures [9, 14]. These field observations indicate that the faulting is dominated by strike-slip displacement as a result of the 


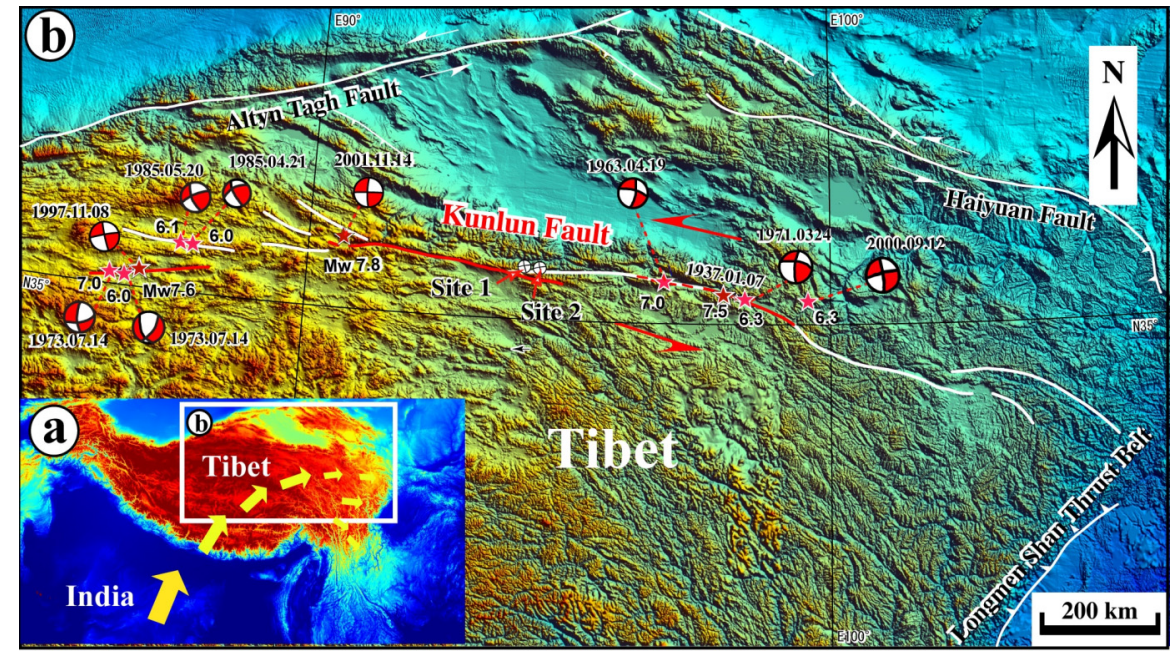

Fig. (1). Landsat image (a) and LTM (Landsat Thermatic Mapper) image (b) showing the seismotectonic features of study area around the Kunlin Fault in the Tibetan Plateau. (a) Small yellow arrows indicate the eastward movement direction of the Tibetan Plateau. Large yellow arrows indicate the movement direction of the Indian plate and the Tibetan Plateau. (b) Beach balls show the focal mechanisms of large

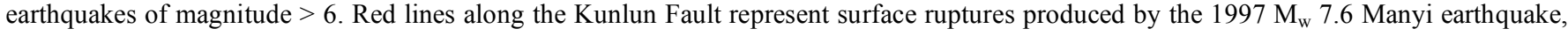
the $2001 \mathrm{Mw} 7.8$ Kunlun earthquake, and the 1937 M 7.5 Tuosuo Lake earthquake. Sites 1 and 2 are the locations of in situ stress measurements (data from Liao et al. [15]).

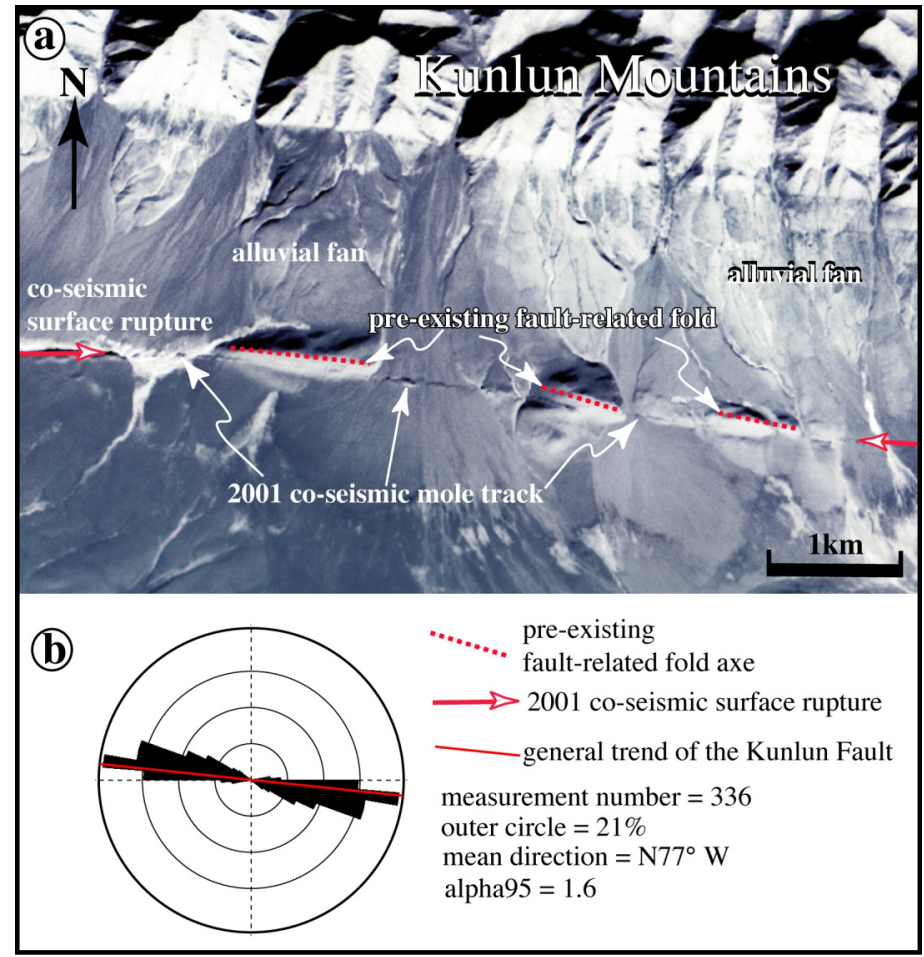

Fig. (2). SPOT image (a) and rose diagram (b) showing the distribution and orientation of mole track structures produced by the $2001 \mathrm{M}_{\mathrm{w}}$ 7.8 Kunlun earthquake and pre-existing fault-related fold structures developed on late Pleistocene-Holocene alluvial fans, at a site located $\sim 6$ $\mathrm{km}$ west of Kusai Lake $\left(92^{\circ} 40^{\prime} \mathrm{E}, 35^{\circ} 50^{\prime} \mathrm{N}\right)$. (a) The 2001 mole tracks and pre-existing fault-related fold structures occurred along the coseismic surface rupture. This image was acquired in December 2001, after the Kunlun earthquake (modified from Lin et al. [14]). (b) The long axes of mole tracks and fault-related folds measured along the $450-\mathrm{km}$-long co-seismic surface rupture zone are oriented within $\sim 10^{\circ}$ of the general trend of the Kunlun Fault $\left(\mathrm{N} 80^{\circ} \mathrm{W}\right)$.

principal compressional stress being oriented perpendicular to the fault. The mole track structures are generally duplicated upon pre-existing fault-related fold structures developed upon alluvial fans that formed in the period between the last glacial (late Pleistocene) and the Holocene (Fig. 2a). The fold axes are orientated subparallel to the general trace of the Kunlun Fault (Fig. 2b), as also observed along the SAF [4], indicating that long-term compressional stress has been oriented sub-perpendicular to the fault in recent geological time (late Pleistocene-Holocene).

The above geological and seismic data indicate that the Kunlun Fault is largely locked by NNE-SSW compressional 
Table 1. Results of Ground Stress Measurement and Estimated Normal and Stress Stresses

\begin{tabular}{|c|c|c|c|c|c|c|}
\hline Sites & Lithology & $\begin{array}{c}\text { Measurement } \\
\text { Depth Below the } \\
\text { Surface (m) }\end{array}$ & $\begin{array}{c}\text { Value of Horizontal } \\
\text { Maximum Principle } \\
\text { Stress (MPa) }\end{array}$ & $\begin{array}{c}\text { Value of } \\
\text { Horizontal } \\
\text { Minimum Principle } \\
\text { Stress (MPa) }\end{array}$ & $\begin{array}{c}\text { Angle Between } \\
\text { Direction of Principle } \\
\text { Stress and the Normal } \\
\text { to Fault Trend (Deg) }\end{array}$ & $\begin{array}{c}\text { Estimated } \\
\text { Normal Stress } \\
\text { (MPa) }\end{array}$ \\
\begin{tabular}{c|c|c|c|c|c|} 
Estimated \\
Shear Stress \\
(MPa)
\end{tabular} \\
\hline \hline 1 & Granite & 18 & 12.9 & 12.1 & 35 & 12.64 \\
\hline
\end{tabular}

In situ measurement stress data from Liao et al. [15]. See Figure 1 for detail locations of Site 1 and 2.

The measurements were taken in August 2001 at Site 1 and September 2001 at Site 2, respectively.

stress, and the recent occurrence of repeated large earthquakes upon the fault suggests its low frictional strength. In situ stress measurements performed near the Kunlun Fault at shallow depths of 14 and $18 \mathrm{~m}$, taken immediately before and after the $2001 \mathrm{M}_{\mathrm{w}} 7.8$ Kunlun earthquake, reveal a low stress state upon the fault [15]. The magnitude and orientation of the principal horizontal stress were measured at the two sites in August and September of 2001, shortly before the Kunlun earthquake (November 2001), revealing maximum and minimum horizontal stresses of 12.9 and 12.1 MPa at Site 1, and 6.8 and 4.4 MPa at Site 2 , respectively. These values showed a marked decrease after the earthquake (Table 1). These in situ measurements indicate that the maximum half horizontal differential stress $\left(\sigma_{1}-\sigma_{2}\right) / 2$ is low at both sites $(<2 \mathrm{MPa}$; Table 1, Fig. 3).

In the case of the SAF, the shear stress along the fault is 10-20 MPa, compatible with the half horizontal differential stress of $100 \mathrm{MPa}$ given the small angle between the maximum principal stress direction normal to the fault [4]. In contrast, the magnitude of half horizontal differential stress upon the Kunlun Fault is one fourth of that estimated on the SAF under the same assumption as that of the SAF that the average shear stress is $20 \mathrm{MPa}$, regardless of the orientation of the maximum principal stress (Fig. 4). Both the half horizontal differential stress and maximum principal stress along the Kunlun Fault plot below the horizontal dashed line in Fig. (3), suggesting that the fault is much weaker than the SAF.

Based on the magnitude and direction of the principal stress, it is possible to obtain the normal stress and shear stress upon a fault plane. Assuming a homogeneous state of stress over the study region, we estimated the magnitude of normal stress $\left(\sigma_{\mathrm{n}}\right)$ and shear stress $\left(\sigma_{\tau}\right)$ along the Kunlun Fault based on in situ stress measurements, as follows:

$\sigma_{\mathrm{n}}=\left[\left(\sigma_{1}+\sigma_{2}\right)+\left(\sigma_{1}-\sigma_{2}\right) \cos 2 \theta\right] / 2$

$\sigma_{\tau}=\left(\sigma_{1}-\sigma_{2}\right) \sin 2 \theta / 2$

where $\sigma_{1}$ and $\sigma_{2}$ are the maximum and intermediate principal stresses, respectively; and $\theta$ is the angle between the direction normal to the fault trend and the maximum principal stress. The calculated results for Sites 1 and 2 are shown in Fig. (4) and Table 1. Both the normal stress and shear stress at the two sites near the Kunlun Fault are much lower than values derived from experimental data based on Byerlee's law [16].

\section{DISCUSSION AND CONCLUSIONS}

Many theories have been proposed to explain fault weakness in the brittle deformation regime, including high pore-fluid pressure [17], acoustic fluidization [18], the presence of a weak core material [19-21], and other mechanisms summarized in Collettini et al. [21]. Recent studies have tended to focus on the role of a weak core material [20-23]. Previous studies have reported that a fault core zone composed of cataclastic rocks is commonly developed along the base of seismogenic fault zones, where large-magnitude earthquakes nucleate and seismic slip is initiated $[3,20,21]$. The results of laboratory experiments and field observations suggest that such core material has a lower frictional coefficient than that of the country rock surrounding the core zone $[20,21]$, thereby explaining the weakness of the SAF [23].

The in situ measurements of stress and calculated shear strength of the Kunlun Fault, as described above, indicate a low value of frictional strength that is an order of magnitude less than the shear strength calculated in laboratory experiments, that deviate markedly from Byerlee's law (Fig. 4), consistent with findings for the SAF. The fact that faultrelated fold structures are oriented at a moderate to high angle to the general trend of the Kunlun Fault indicates that the fault is mechanically locked. However, the high rate of strike-slip displacement $(>10 \mathrm{~mm} / \mathrm{yr})$ and short recurrence interval (300-400 years) for large-magnitude earthquakes along the fault $[10,24-26]$ demonstrate that it is unlocked and currently active. Furthermore, more than 10 moderate to large $(M>6.0)$ earthquakes have occurred on the Kunlun Fault over the past century, with four $M \geq 7.0$ events producing surface ruptures of $40-450 \mathrm{~km}$ in length [10]. GPS (Global Position System) data show that the strike-slip rate along the Kunlun Fault is large, up to $18 \mathrm{~mm} / \mathrm{yr}$, which is comparable with that of the SAF [27]. Accordingly, the accumulated geological, seismological and geophysical evidence outlined above indicate that the fault is rheologically weak. It is reported that a mechanically-weak core zone composed of cataclastic fault rocks is popularly developed in a mature active fault zone, which constrains the fault strength of seismogenic zone [3, 20]. Geologic evidence shows that the Kunlun Fault is a mature and longlive active fault [12] with a large strike-slip of $>10 \mathrm{~km} \mathrm{[28].}$ Therefore, we also propose that a weak core zone composed of cataclastic fault rocks is present in the seismogenic zone that constrains the rheological strength of the Kunlun Fault.

The weakness of the Kunlun Fault is important in understanding the deformation patterns of intracontinental faults, and is related to the larger problem of the nature of crustal growth of the Tibetan Plateau. Analysis of the fault strength and long-term behavior of active strike-slip faults would provide new insight into the tectonic behavior of intracontinental faults and the mode of continental deformation and nature of seismic hazards upon the Tibetan 


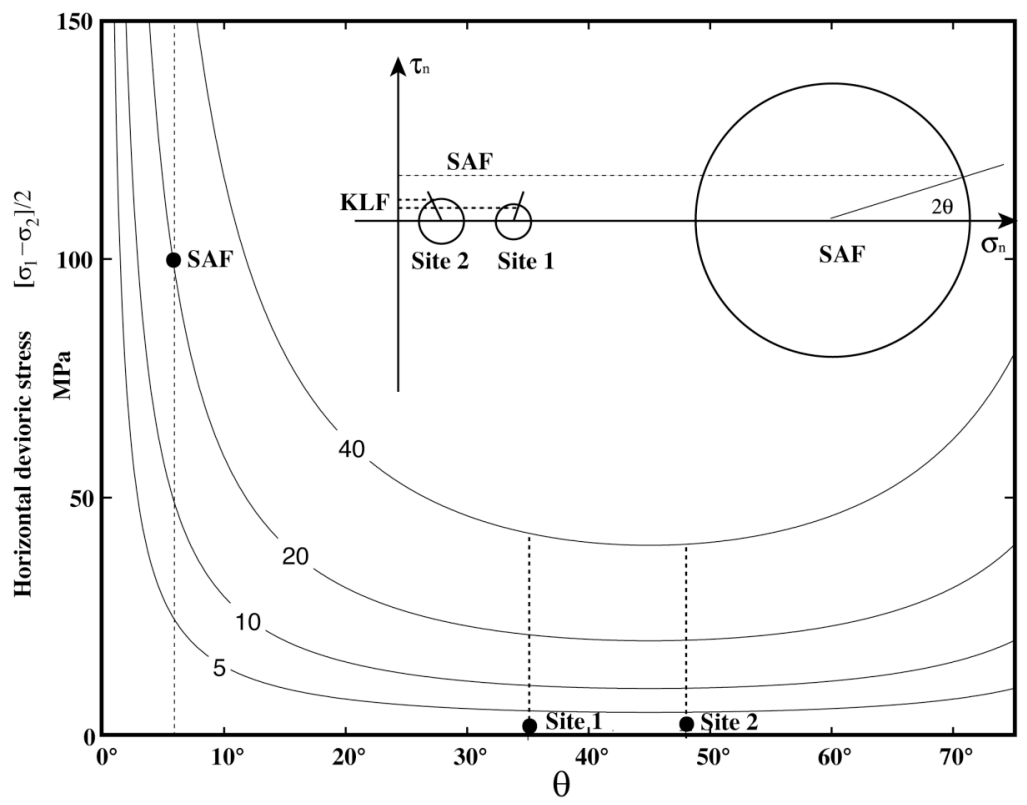

Fig. (3). Plot of the $\sigma_{1}$ stress orientation $(\theta) v s$ the half horizontal differential stress $\left(\sigma_{1}-\sigma_{2}\right) / 2$ for lines of constant shear-stress $\sigma_{\tau}$. Both the maximum shear stress and horizontal differential stress along the Kunlun Fault (KLF, Sites 1 and 2; see Fig. (1) for site locations) are considerably lower than that along the San Andreas Fault (SAF; dashed line). Based on an average strike of N80 ${ }^{\circ} \mathrm{W}$ for the Kunlun Fault, $\theta$ is calculated to be $35^{\circ}$ at Site 1 and $42^{\circ}$ at Site 2 .

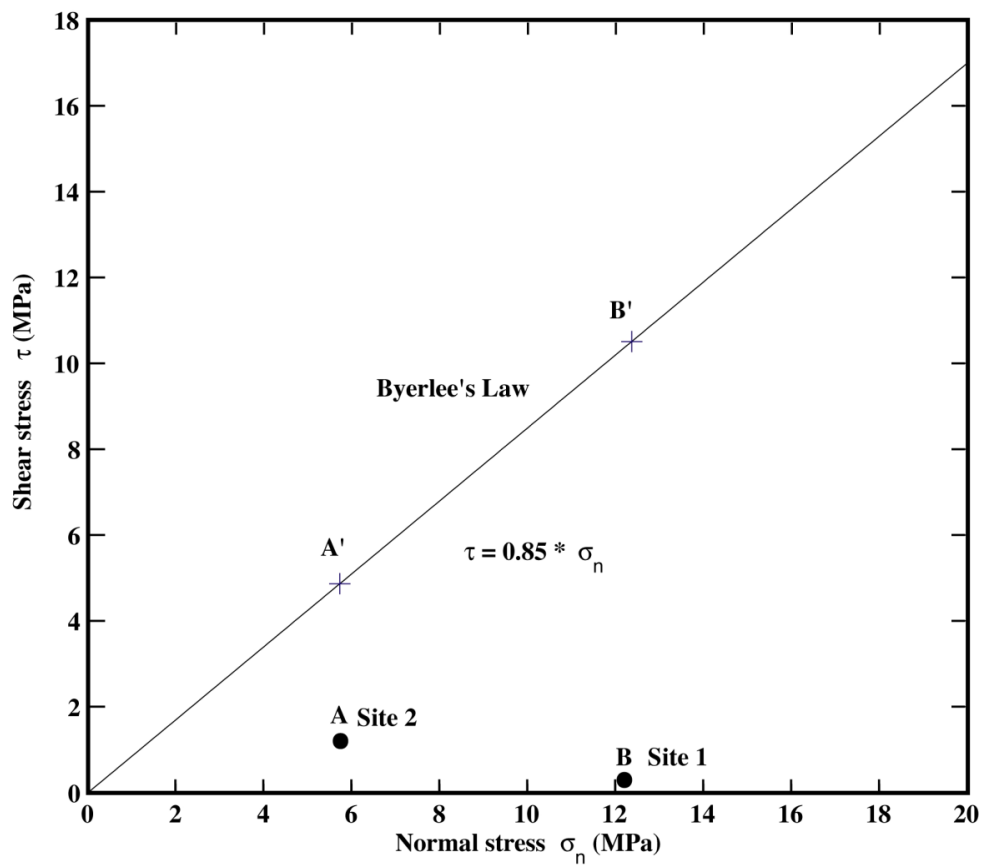

Fig. (4). Shear stresses calculated from in situ measurement data at Sites 1 and 2 along the Kunlun Fault, plotted as a function of normal stress. The trend line is after Byerlee [16], based on laboratory experiments for a variety of rocks and minerals.

Plateau. The fact that the slip rate of the Kunlun Fault decreases to the east and approaches zero at its eastern termination, together with the gradational change in the recurrence interval of large earthquakes from 300-400 years along the western part of the fault to 1000 years along the eastern part [10], suggests that the Kunlun Fault plays an important role as a transfer fault in the eastward extrusion of the Tibetan Plateau.

The Kunlun Fault is a major, active, left-lateral strike-slip fault upon the Tibet Plateau [10]. Analysis of the fault strength of the fault is important in understanding the tectonic behavior of strike-slip faults and in assessing the mode of continental deformation of the Tibet Plateau. The deformation mode of the Kunlun Fault is in agreement with the models proposed previously [29, 30], which assume a weak fault. Although these models were originally developed for the lower crust (i.e., ductile rather than brittle deformation), the deformation patterns observed along the Kunlun Fault suggest that the fault zone rheology in the upper crust, as discussed above, is consistent with these 
models and that the weakness assumed in these models could be attributed to the presence of a weak core zone of fault rocks in the seismogenic zone. The long left-lateral strikeslip history [10,12, 24-26] and large horizontal displacement $(>10 \mathrm{~km})$ [28] along the Kunlun Fault, which indicate repeated strike-slip displacement, also support the above idea that the fault zone is rheologically weaker than the surrounding basement rock and thereby more susceptible to seismic slip. Accordingly, the weak Kunlun Fault plays an important role in response to the eastward extrusion of the Tibetan Plateau by strike-slip faulting and releasing the seismic strain energy caused by the ongoing continental collision between the India Plate and the Eurasian Plate.

In summary, the weakness of the Kunlun Fault is consistent with the observed deformation characteristics and current seismicity, and an explanation of the weakness in terms of a weak core material provides a clearer picture of the frontier of the zone of eastern extrusion of the Tibetan Plateau. Based on the above data, we conclude that the Kunlun Fault is a weak strike-slip fault that plays an important role in the eastward extrusion of the Tibetan Plateau.

\section{ACKNOWLEDGEMENTS}

We are grateful to four anonymous reviewers for their critical reviews that help to improve the manuscript. We thank Mr. M. Nishikawa for his assistance in processing remote sensing images. This work was supported by the Shizuoka University and the Science Project (Project Number 18340158 for A. Lin) of the Ministry of Education, Culture, Sports, Science and Technology of Japan.

\section{RERERENCES}

[1] J.N. Brune, T.L. Henyey, and R.F. Roy, "Heat flow, stress, and rate of slip along the San Andreas fault, California", J. Geophys. Res., vol. 74, pp. 3821-3827, July 1969.

[2] M.D. Zoback, Z.L. Zoback, V.S. Mount, J. Suppe, J.P. Eaton, J.H. Healy, D. Oppenheimer, P. Reasenberg, L. Jones, C.B. Raleigh, I.G. Wong, O. Scotti, and C. Wentworth, "New evidence for the state of stress on the San Andreas fault system", Science, vol. 238, pp. 11051111, Nov 1987.

[3] Lin, A., Fossil Earthquakes: The Formation and Preservation of Pseudotachylytes, Springer-Verlag, Berlin, 2008.

[4] V. S. Mount, and J. Suppe, "State of stress near the San Andreas fault: Implications for wrench tectonics", Geology, vol. 15, pp. 1143-1146, Dec 1987.

[5] J. Townend, and M.D. Zoback, "Regional tectonic stress near the San Andreas fault in central and southern California", Geophys. Res. Lett., vol. 31, L15S11, July 2004.

[6] P.H. Scholz, "Evidence for a strong San Andreas fault", Geology, vol. 28, pp. 163-166, Feb 2000.

[7] J. L. Hardebeck, and A.J. Michael, "Stress orientations at intermediate angles to the San Andreas Fault, California", J. Geophys. Res., vol. 109, B11303, Nov 2004.

[8] Editorial Board, State Seismological Bureau (EBSSB), Lithospheric dynamics atlas of China, China Cartographic Publishing House: Beijing, 1989.
[9] A. Lin, B. Fu, J. Guo, Q. Zeng, G. Dang, W. He, and Y. Zhao, "Coseismic strike-slip and rupture length produced by the $2001 \mathrm{M}_{\mathrm{s}} 8.1$ central Kunlun earthquake", Science, vol. 296, pp. 2015-2017, Jun 2002

[10] A. Lin, and J. Guo, "Non-uniform slip rate and millennial recurrence interval of large earthquakes on the eastern segment along the Kunlun fault, northern Tibet", Bull. Seismol. Soc. Am., vol. 98, pp. 2866-2878, Dec 2008.

[11] P. Zhang, Z. Shen, M. Wang, W. Gan, R. Buergmann, P. Molnar, Q. Wang, Z. Niu, J. Sun, J. Wu, H. Sun, and X. You, "Continuous deformation of the Tibetan Plateau from Global Positioning System data", Geology, vol. 32, pp. 809-812, Sep 2004.

[12] P. Tapponnier, Z. Xu, F. Roger, B. Meyer, N. Arnaud, G. Wittlinger, and J. Yang, "Oblique stepwise rise and growth of the Tibet Plateau", Science, vol. 294, pp. 1671-1677, Nov 2001.

[13] G. Pelzer, F. Cramp, and G. King, "Evidence of nonlinear elasticity of the crust from the Mw 7.6 Manyi earthquake", Science, vol. 286, pp. 272-276, Oct 1999.

[14] A. Lin, J. Guo, and B. Fu, "Co-seismic mole-track structures produced by the $2001 \mathrm{M}_{\mathrm{s}}$ 8.1 Central Kunlun earthquake, China", J. Struct. Geol., vol. 26, pp. 1511-1519, Aug 2004.

[15] C. Liao, C. Zhang, M. Wu, Y. Ma and M. Ou, "Stress change near the Kunlun fault before and after the Ms 8.1 Kunlun earthquake", Geophys. Res. Lett., vol. 30(20), pp. 2027, Oct 2003.

[16] J.D. Byerlee, "Friction of rocks", Pure Appl. Geophys., vol. 116, pp. 615-629, 1978.

[17] D.R. Faulkner, T.M. Mitchell, D. Healy, and M.J. Heap, "Slip on 'weak' faults by the rotation of regional stress in the fracture damage zone", Nature, vol. 444, pp. 922-925, Dec 2006.

[18] H.J. Melosh, "Dynamic weakening of faults by acoustic fluidization", Nature, vol. 397, pp. 601-606, Feb 1996.

[19] F.M. Chester, and J.M. Logan, "Composite planar fabric of gouge from the Punchbowl Fault, California", J. Struct. Geol., vol. 9, pp. 621-634, Mar 1987.

[20] A. Lin, "S-C cataclasite in granitic rock", Tectonophysics, vol. 304, pp. 257-273, Apr 1999.

[21] C. Collettini, A. Niemeijer, C. Viti, and C. Marone, "Fault zone fabric and fault weakness", Nature, vol. 462, pp. 907-910, Dec 2009.

[22] D.E. Moore, and M.J. Rymer, "Talc-bearing serpentinite and the creeping section of the San Andreas fault", Nature, vol. 448, pp. 795797, Aug 2007.

[23] B.M. Carpenter, C. Marone, and D.M. Saffer, "Frictional behavior of materials in the 3D SAFOD volume", Geophys. Res. Lett., vol. 36, L05302, Mar 2009.

[24] J. Guo, A. Lin, T. Maruyama, J. Zheng, and G. Sun, "New constraints on recent large earthquakes along the Xidatan-Dongdatan segment of the Kunlun fault, western China", Bull. Seismol. Soc. Am., vol. 96, pp. 48-58, Feb 2006.

[25] A. Lin, J. Guo, K. Kano, and A. Yasuo, "Average slip rate and recurrence interval of large-magnitude earthquakes on the western segment of the strike-slip Kunlun fault, northern Tibet.” Bull Seismol Soc. Am., vol. 96, pp. 1597-1611, Oct 2006.

[26] A. Lin, and J. Guo, "Pre-seismicity-induced liquefaction along the western segment of the strike-slip Kunlun fault, northern Tibet", Geol Soc Lond, [ Special Publications], vol. 316, pp. 145-154. June 2009.

[27] Q. Wang, P. Zhang, J.F. Freymueller, R. Bilham, K.M. Larson, X. Lai, X. You, Z. Nie, J. Wu, Y. Li, J. Liu, Z. Yang, and Q. Chen, "Presentday crustal deformation in China constrained by global positional system measurements", Science, vol. 294, 574-578, Oct 2001.

[28] W.S.F. Kidd, and P. Molnar, "Quaternary and active faulting observed on the 1985 Academia-Sinica Royal-Society Geotraverse of Tibet", Philos. Trans. R. Soc. Lond., vol. 327, pp. 337-363, Dec 1988.

[29] D.C.P. Peacock, "Displacements and segment linkage in strike-slip fault zones", J. Struct. Geol., vol. 13, pp. 1025-1035, Sep 1991.

[30] T.D. Barr, and G.A. Houseman, "Deformation fields around a fault embedded in a non-linear ductile medium", Geophys. J. Int., vol. 125, pp. 473-490, May 1996. 